(c) American Dairy Science Association, 2005.

\title{
Short Communication: Comparison of Covered and Uncovered Schreiber Test for Cheese Meltability Evaluation
}

\author{
A. Altan, ${ }^{1}$ M. Turhan, ${ }^{2}$ and S. Gunasekaran ${ }^{3}$ \\ ${ }^{1}$ Department of Food Engineering, University of Gaziantep, Gaziantep 27310, Turkey \\ ${ }^{2}$ Department of Food Engineering, University of Mersin, Ciftlikkoy, Mersin 33343, Turkey \\ ${ }^{3}$ Biological Systems Engineering Department, University of Wisconsin-Madison, Madison 53706
}

\begin{abstract}
Schreiber meltability tests were performed on glass Petri dishes, with and without the Petri dish cover placed over the cheese samples, at 100,150 , and $232^{\circ} \mathrm{C}$. Meltability of different process cheese and Cheddar cheese samples was determined based on the melt spread distance and area. At the test temperature of $232^{\circ} \mathrm{C}$, the covered Schreiber was significantly superior to the uncovered test because of no crust formation, no browning, and a circular melting pattern, which were attributed to the barrier effect of covering the cheese samples (which inhibits moisture loss during the test). The covered Schreiber test data were statistically more robust as measured by the lower average coefficient of variation than the data from the traditional uncovered Schreiber test.
\end{abstract}

(Key words: cheese meltability, Cheddar cheese, process cheese, Schreiber test)

Abbreviation key: $\mathbf{A I}=$ area index, $\mathbf{C I}=$ circle index, $\mathbf{C O S}=$ covered Schreiber test, $\mathbf{C V}=$ mean coefficient of variation, UCS = uncovered Schreiber test.

Cheese meltability is defined as the ease and extent at which cheese will flow upon heating (Gunasekaran and $\mathrm{Ak}, 2003)$. It is an important functional property especially for cheeses used in foods consumed after heat treatment.

Many attempts have been made to measure and control cheese meltability. As part of these efforts a battery of meltability tests has been developed, which can be divided into empirical methods and objective methods. The empirical tests depend on measuring dimensional changes in the cheese sample upon melting, such as diameter, height, etc. (Arnott et al., 1957; Kosikowski, 1977); the objective methods rely on determining intrinsic rheological properties of the cheese such as viscosity,

Received September 13, 2004.

Accepted November 7, 2004.

Corresponding author: Sundaram Gunasekaran; e-mail: guna@ wisc.edu. viscoelasticity, etc. (Wang et al., 1998; Kuo et al., 2000). Gunasekaran and $\mathrm{Ak}$ (2003) documented and discussed the various cheese meltability tests.

Despite being empirical, the Schreiber test (Kosikowski, 1977) is by far the most widely used in the industry perhaps because of its simplicity. According to the original Schreiber test, a cylindrical cheese specimen (41 $\mathrm{mm}$ in diameter, $4.8 \mathrm{~mm}$ in height) centered on a concentrically numbered target-type graph is heated in an oven set at $232^{\circ} \mathrm{C}$ for $5 \mathrm{~min}$; the longest flow line from the center to the edge of the melt is used as the cheese meltability (Kosikowski, 1977). Major drawbacks of this procedure are excessive and uncontrolled heating, drying, crust formation, and browning, and inaccurate flow line measurement in case of noncircular melting $(\mathrm{Mu}-$ thukumarappan et al., 1999; Gunasekaran and Ak, 2003).

Considering its widespread use, many researchers investigated the effect of heating temperature, mode, and surface, sample geometry and dimension, and method for measuring the melting to overcome many of the inherent problems of the Schreiber test (Park et al., 1984; Muthukumarappan et al., 1999; Wang and Sun, 2001, 2002). However, the effect of moisture loss during heating has not been investigated as a potential source of error in Schreiber test meltability results. It is well known that moisture loss during heating, especially in low-fat cheeses, affects the cheese properties. The noncircular melt spread, crust formation, and scorching at elevated temperatures are some of the problems attributed to moisture loss during heating. To minimize moisture loss during heating of the cheese sample in a Petri dish, we enclosed the sample with the Petri dish cover. The results of the Schreiber meltability test with and without the Petri dish cover are presented herein.

Four process cheeses ( 2 high melt and 2 medium melt) and 3 Cheddar cheeses (aged, medium aged, and mild aged) were obtained from Schreiber Foods, Inc. (Green Bay, WI). The cheeses were stored at $5^{\circ} \mathrm{C}$ until sample preparation. Samples were cut into 5-mm-thick slices using a hand-operated slicer (model 1042, Rival Co., Kansas City, MO) and then into 41-mm-diameter 
Table 1. Chemical composition of cheese samples tested.

\begin{tabular}{lllll}
\hline Cheese type & Moisture (\%) & Fat $(\%)$ & Salt $(\%)$ & $\mathrm{pH}$ \\
\hline Process cheese & & & & \\
High melt A & 48.8 & 22.3 & 2.00 & 5.99 \\
High melt B & 49.0 & 22.0 & 2.11 & 5.88 \\
Medium melt A & 39.8 & 30.5 & 2.32 & 6.17 \\
Medium melt B & 40.6 & 30.0 & 2.34 & 6.09 \\
Cheddar cheese & & & & \\
$\quad$ Aged & 36.0 & 33.5 & 1.56 & 5.05 \\
$\quad$ Medium aged & 36.0 & 33.0 & 2.12 & 5.32 \\
Mild aged & 39.1 & 31.1 & 1.70 & 5.36 \\
\hline
\end{tabular}

discs using a cork borer. Cheese specimens were kept in plastic bags at $5^{\circ} \mathrm{C}$ until testing.

Chemical analyses of the samples were performed according to published methods and are presented in Table 1. Moisture content was determined by the AOAC oven method at $100^{\circ} \mathrm{C}$ for $24 \mathrm{~h}$ (AOAC, 1995). Fat was determined by the Babcock method (Bradley et al., 1992), salt was determined colorimetrically (Johnson and Olson, 1985), using a Chloride Analyzer 926 (Corning, Medfield, MA), and $\mathrm{pH}$ was measured by $\mathrm{pH}$ meter (Orion 420A) with a solid RJ pH probe and Orion ATC automatic temperature compensation probe.

Schreiber test was performed by heating cheese specimens on a glass Petri dish with (mass $=65.34 \pm 2.17$ g; diameter $=100 \mathrm{~mm}$, and height $=21 \mathrm{~mm})$ and without the Petri dish cover $($ mass $=37.41 \pm 0.93 \mathrm{~g}$; diameter $=$ $94.05 \mathrm{~mm}$, height $=19.41 \mathrm{~mm}$ ) in an oven (Blue-M, model OV-490A-2, Blue-M Electric Company, Blue Island, IL) at 100,150 , and $232^{\circ} \mathrm{C}$. After 5 min, cheese melts were removed from the oven, and cooled at room temperature for $30 \mathrm{~min}$. The cheese flow was determined by measuring the spread diameter and area. The spread diameter was measured using concentrically numbered target-type templates placed face up at the bottom of the Petri dishes. Diameter of the innermost circle was $41 \mathrm{~mm}$ and the diameter of the subsequent circles increased by $2.5 \mathrm{~mm}$. The circles were numbered sequentially from 0 to 10 starting from the smallest. The template was divided into 8 equal sectors according to Park et al. (1984). At the start of a melt test, a cheese specimen would fit inside the circle "0". The Schreiber test was repeated 3 times for each cheese sample taken from similar batch but different molds. The replicate samples were tested individually at different times.

Two meltability indices were calculated: circle index (CI) and area index (AI). Circle index is the average of the cheese spread circle numbers at each of the 8 sector lines (Figures 1,2); and AI is the increase in cheese surface area upon melting as measured by a computer imaging system. The imaging system included a CCD video camera (model VDC 3874, Sanyo, San Diego, CA), light source, digitizer (PC Vision Inc., Quebec, Canada), computer (model 486SX; Diversified Systems, Issaquah, WA), a 15-inch video monitor (model Ectochrome, Home Automation Systems Inc., Irvine, CA), and Optimas image processing software (Bioscan Inc., Edmonds, WA).

All measurements were conducted in triplicate. Statistical analyses were performed by ANOVA using SPSS software (SPSS 8.0; SPSS Inc, Chicago, IL).

Figures 1 and 2 show the typical appearances of the process and Cheddar cheese melts, respectively, obtained by covered Schreiber test (COS) and uncovered Schreiber test (UCS). Apparent drying and crust formation was observed on all UCS samples melted at 100 and $150^{\circ} \mathrm{C}$; neither drying nor crust formation was detected on COS samples. The UCS samples tested at
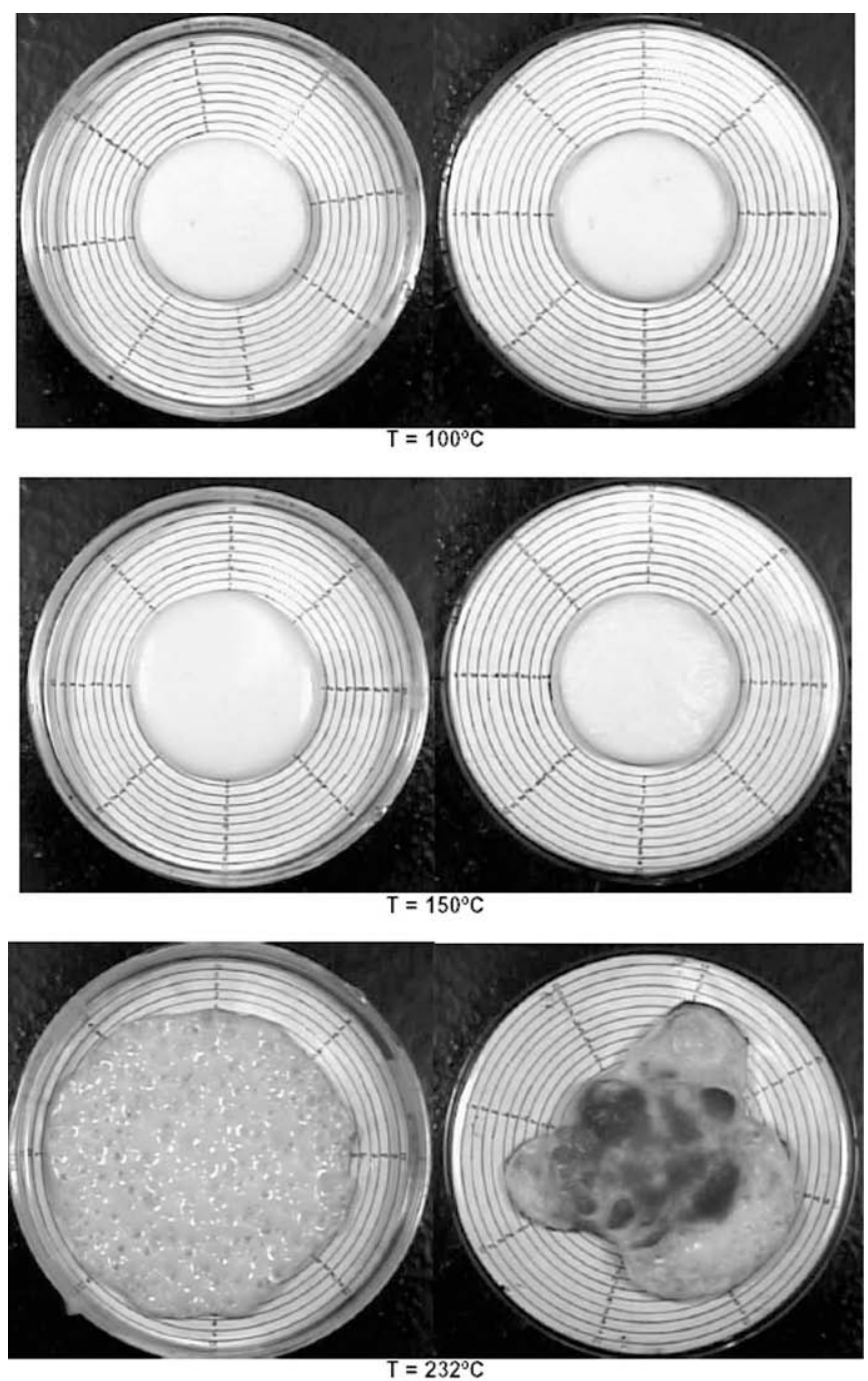

Figure 1. Melt spreads of process cheese (medium melt A) obtained at different test temperatures by covered (left) and uncovered (right) Schreiber tests. 

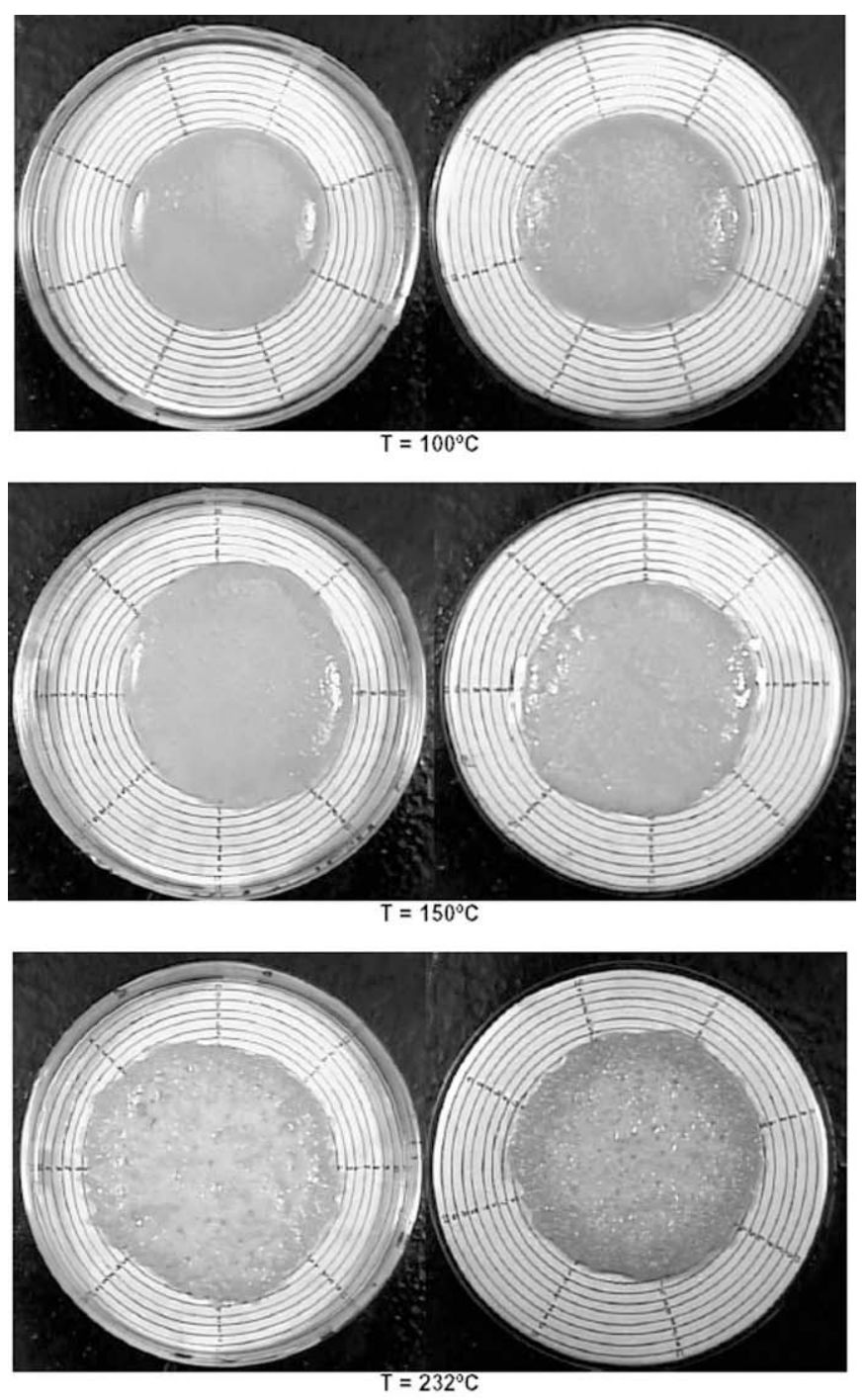

Figure 2. Melt spreads of Cheddar cheese (medium aged) obtained at different test temperatures by covered (left) and uncovered (right) Schreiber tests.

$232^{\circ} \mathrm{C}$ were severely scorched on the edges and on the melt surface, which was nonexistent in the COS samples. Furthermore, the COS samples were generally more circular, especially the process cheese samples tested at $232^{\circ} \mathrm{C}$.

As expected, both $\mathrm{AI}$ and $\mathrm{CI}$ increased with increasing test temperature for all cheese samples (Tables 2, 3). The increase in AI was more pronounced than the increase in CI. For process cheese samples, except one sample at $100^{\circ} \mathrm{C}, \mathrm{COS}$ gave significantly higher $\mathrm{AI}$ and CI than UCS at the same temperatures. This supported our initial hypothesis that cheese melt test results could improve if moisture loss from cheese samples was inhibited. The same trend was observed with the Cheddar cheese samples tested at $232^{\circ} \mathrm{C}$. At $100^{\circ} \mathrm{C}$ and $150^{\circ} \mathrm{C}$, however, the test data of COS and UCS were numerically, but not statistically, different. The test temperature of $232^{\circ} \mathrm{C}$ is high as it can cause scorching of the samples (Muthukumarappan et al., 1999; Figure 1, 2). However, such high temperatures may be necessary for testing of some low-melt and specialty cheeses. In such cases, and for the sake of using uniform test conditions, selecting $232^{\circ} \mathrm{C}$ may be preferable. This is clear, judging from the current industry practice. In which case, based on our results, it would be highly desirable to perform the Schreiber tests with the glass Petri dish lid placed over the cheese samples. In addition to leaving the samples unscorched and ensuring that the melt spread is circular, the larger numerical melt spread values obtained via covered Schreiber tests may assist in discriminating samples with similar meltabilities.

The robustness of COS and UCS data was evaluated by calculating coefficient of variation (CV) of the $\mathrm{AI}$ and CI. The mean values presented in Table 4 indicate that the data variation decreases for both COS and UCS with increasing test temperature. Moreover, at all test temperatures, mean CV values for COS data were lower than those for UCS data. The AI values obtained with $\mathrm{COS}$ at $232^{\circ} \mathrm{C}$ were by far the most precise as observed from the low $\mathrm{CV}$ value, and hence became our recommended test conditions.

Measuring the melt spread area and the AI is more demanding (in terms of time and resources) for the industry than measuring the CI. Therefore, we attempted to determine the possible relationship between these 2 meltability metrics. We obtained strong linear relationships $\left(R^{2} \geq 0.96\right)$ between $A I$ and CI values from both COS and UCS tests (Table 5). This correlation indicates that the industry might use CI as the preferred meltability index for routine tasks and use the AI for research and development purposes. However, neither the AI or CI values obtained by COS and UCS tests correlate $\left(R^{2} \leq 0.52\right)$, indicating that the COS test data indeed vary substantially from those of the traditional UCS data.

Drying, crust formation, and browning, and noncircular melting encountered in the conventional Schreiber test due to high temperature can be eliminated by conducting the tests with the glass Petri dish lid placed over the samples. The covered test performed at $232^{\circ} \mathrm{C}$ resulted in the largest numerical values and the smallest coefficient of variation for different process cheese and Cheddar cheese samples. Thus, we recommend performing Schreiber cheese meltability tests at $232^{\circ} \mathrm{C}$ in a glass Petri dish with the samples covered with the glass Petri dish lid. The measuring melt spread distance (CI) will be sufficient for routine tasks; but measuring melt spread area (AI) may be necessary for research and development purposes. Further investiga- 
Table 2. Meltability of cheese samples (area index, $\mathrm{cm}^{2}$ ) after covered (COS) and uncovered Schreiber test (UCS).

\begin{tabular}{|c|c|c|c|c|c|c|}
\hline \multirow[b]{2}{*}{ Cheese type } & \multicolumn{2}{|c|}{$100^{\circ} \mathrm{C}$} & \multicolumn{2}{|c|}{$150^{\circ} \mathrm{C}$} & \multicolumn{2}{|c|}{$232^{\circ} \mathrm{C}$} \\
\hline & $\cos$ & UCS & $\cos$ & UCS & $\mathrm{COS}$ & UCS \\
\hline \multicolumn{7}{|l|}{ Process cheese } \\
\hline High melt A & $11.70 \pm 0.2^{\mathrm{a}}$ & $2.10 \pm 0.9^{b}$ & $16.80 \pm 1.1^{\mathrm{a}}$ & $8.90 \pm 0.1^{b}$ & $36.20 \pm 0.6^{\mathrm{a}}$ & $22.40 \pm 0.8^{\mathrm{b}}$ \\
\hline High melt $B$ & $11.40 \pm 1.2^{\mathrm{a}}$ & $2.90 \pm 1.3^{b}$ & $23.7 \pm 0.8^{\mathrm{a}}$ & $10.30 \pm 0.2^{\mathrm{b}}$ & $33.90 \pm 0.3^{\mathrm{a}}$ & $29.90 \pm 0.5^{\mathrm{b}}$ \\
\hline Medium melt A & $0.30 \pm 0.3^{\mathrm{a}}$ & $0.60 \pm 0.6^{\mathrm{a}}$ & $5.80 \pm 0.5^{\mathrm{a}}$ & $0.90 \pm 0.4^{\mathrm{b}}$ & $30.30 \pm 0.4^{\mathrm{a}}$ & $17.50 \pm 0.6^{\mathrm{b}}$ \\
\hline Medium I & $4.00 \pm 1.4^{\mathrm{a}}$ & $0.60 \pm 0.5^{b}$ & $9.50 \pm 0.4^{\mathrm{a}}$ & $1.10 \pm 0.4^{\mathrm{b}}$ & $17.70 \pm 1.2^{\mathrm{a}}$ & $6.20 \pm 0.4^{\mathrm{b}}$ \\
\hline \multicolumn{7}{|l|}{ Cheddar chee } \\
\hline Aged & $0.46 \pm 0.2^{\mathrm{a}}$ & $3.16 \pm 0.9^{b}$ & $16.46 \pm 3.4^{\mathrm{a}}$ & $19.20 \pm 2.3^{\mathrm{a}}$ & $32.16 \pm 0.5^{\mathrm{a}}$ & $23.86 \pm 1.0^{\mathrm{b}}$ \\
\hline Medium ag & $5.66 \pm 1.4^{\mathrm{a}}$ & $6.20 \pm 1.7^{\mathrm{a}}$ & $13.03 \pm 0.4^{\mathrm{a}}$ & $13.00 \pm 0.4^{\mathrm{a}}$ & $18.43 \pm 0.5^{\mathrm{a}}$ & $14.73 \pm 0.7^{\mathrm{b}}$ \\
\hline Mild aged & $7.91 \pm 1.4^{\mathrm{a}}$ & $8.86 \pm 0.5^{\mathrm{a}}$ & $14.81 \pm 0.8^{\mathrm{a}}$ & $13.59 \pm 1.3^{\mathrm{a}}$ & $18.51 \pm 0.4^{\mathrm{a}}$ & $15.31 \pm 0.2^{\mathrm{b}}$ \\
\hline
\end{tabular}

${ }^{a, b}$ Under the same temperature, means in the same row with different superscripts differ $(P<0.05)$.

Table 3. Meltability of cheese samples (circle index) after covered (COS) and uncovered Schreiber test (UCS).

\begin{tabular}{|c|c|c|c|c|c|c|}
\hline \multirow[b]{2}{*}{ Cheese type } & \multicolumn{2}{|c|}{$100^{\circ} \mathrm{C}$} & \multicolumn{2}{|c|}{$150^{\circ} \mathrm{C}$} & \multicolumn{2}{|c|}{$232^{\circ} \mathrm{C}$} \\
\hline & $\cos$ & UCS & $\cos$ & UCS & COS & UCS \\
\hline \multicolumn{7}{|l|}{ Process cheese } \\
\hline High melt A & $3.1 \pm 0.2^{\mathrm{a}}$ & $0.5 \pm 0.1^{\mathrm{b}}$ & $4.0 \pm 0.10^{\mathrm{a}}$ & $2.5 \pm 0.05^{\mathrm{b}}$ & $7.8 \pm 0.28^{a}$ & $4.4 \pm 0.25^{b}$ \\
\hline High melt $B$ & $3.1 \pm 0.3^{\mathrm{a}}$ & $0.6 \pm 0.1^{\mathrm{b}}$ & $5.0 \pm 0.75^{\mathrm{a}}$ & $2.7 \pm 0.1^{\mathrm{b}}$ & $7.9 \pm 0.29^{a}$ & $6.3 \pm 0.20^{\mathrm{b}}$ \\
\hline Medium melt A & $0.0 \pm 0.0^{\mathrm{a}}$ & $0.0 \pm 0.0^{\mathrm{a}}$ & $1.6 \pm 0.03^{a}$ & $0.0 \pm 0.0^{\mathrm{b}}$ & $6.7 \pm 0.25^{\mathrm{a}}$ & $4.6 \pm 0.26^{\mathrm{b}}$ \\
\hline Medium melt B & $1.0 \pm 0.1^{\mathrm{a}}$ & $0.0 \pm 0.0^{\mathrm{a}}$ & $2.8 \pm 0.18^{\mathrm{a}}$ & $0.0 \pm 0.0^{b}$ & $4.2 \pm 0.15^{\mathrm{a}}$ & $1.4 \pm 0.12^{\mathrm{b}}$ \\
\hline \multicolumn{7}{|l|}{ Cheddar chee } \\
\hline Aged & $0.0 \pm 0.0^{\mathrm{a}}$ & $0.7 \pm 0.4^{\mathrm{a}}$ & $4.2 \pm 0.75^{\mathrm{a}}$ & $4.3 \pm 0.28^{a}$ & $7.6 \pm 0.09^{a}$ & $5.4 \pm 0.29^{b}$ \\
\hline Medium aged & $1.4 \pm 0.4^{\mathrm{a}}$ & $1.9 \pm 0.2^{\mathrm{a}}$ & $3.4 \pm 0.15^{\mathrm{a}}$ & $3.3 \pm 0.01^{\mathrm{a}}$ & $4.8 \pm 0.31^{\mathrm{a}}$ & $3.7 \pm 0.12^{\mathrm{b}}$ \\
\hline Mild aged & $2.0 \pm 0.3^{\mathrm{a}}$ & $2.2 \pm 0.1^{\mathrm{a}}$ & $3.8 \pm 0.21^{\mathrm{a}}$ & $3.3 \pm 0.23^{\mathrm{a}}$ & $4.7 \pm 0.10^{a}$ & $3.7 \pm 0.06^{\mathrm{b}}$ \\
\hline
\end{tabular}

${ }^{\mathrm{a}, \mathrm{b}}$ Under the same temperature, means on the same row with different superscripts differ $(P<0.05)$.

Table 4. Average of mean coefficient of variation (CV) for the meltability indices of all cheese samples after covered (COS) and uncovered Schreiber test (UCS).

\begin{tabular}{|c|c|c|c|c|c|c|}
\hline \multirow[b]{2}{*}{ Meltability index ${ }^{1}$} & \multicolumn{2}{|c|}{$100^{\circ} \mathrm{C}$} & \multicolumn{2}{|c|}{$150^{\circ} \mathrm{C}$} & \multicolumn{2}{|c|}{$232^{\circ} \mathrm{C}$} \\
\hline & $\mathrm{CO}$ & UCS & $\cos$ & UCS & $\cos$ & UCS \\
\hline $\mathrm{AI}$ & 27.51 & 39.01 & 6.18 & 12.71 & 2.81 & 4.01 \\
\hline $\mathrm{CI}$ & 17.41 & 19.23 & 5.94 & 6.99 & 4.17 & 5.31 \\
\hline
\end{tabular}

${ }^{1} \mathrm{AI}=$ Area index; $\mathrm{CI}=$ circle index.

Table 5. Correlation between area index (AI) and circle index (CI), and covered (COS) and uncovered Schreiber test (UCS) (Equations were forced through 0, 0).

\begin{tabular}{|c|c|c|c|c|c|c|}
\hline \multirow[b]{3}{*}{ Correlation } & \multicolumn{6}{|c|}{ Test temperature $\left({ }^{\circ} \mathrm{C}\right)$} \\
\hline & \multicolumn{2}{|l|}{100} & \multicolumn{2}{|l|}{150} & \multicolumn{2}{|l|}{232} \\
\hline & Equation & $\mathrm{R}^{2}$ & Equation & $\mathrm{R}^{2}$ & Equation & $\mathrm{R}^{2}$ \\
\hline $\begin{array}{l}\text { COS } \\
\text { AI vs. CI }\end{array}$ & $\mathrm{AI}=3.76 \mathrm{CI}$ & 0.996 & $\mathrm{AI}=3.96 \mathrm{CI}$ & 0.986 & $\mathrm{AI}=4.30 \mathrm{CI}$ & 0.960 \\
\hline $\begin{array}{l}\text { UCS } \\
\text { AI vs. CI }\end{array}$ & $\mathrm{AI}=3.58 \mathrm{CI}$ & 0.995 & $\mathrm{AI}=4.08 \mathrm{CI}$ & 0.975 & $\mathrm{AI}=4.38 \mathrm{CI}$ & 0.971 \\
\hline $\begin{array}{l}\mathrm{AI} \\
\text { COS vs. UCS }\end{array}$ & $\mathrm{COS}=0.89 \mathrm{UCS}$ & -0.447 & $\mathrm{COS}=1.17 \mathrm{UCS}$ & -0.512 & $\mathrm{COS}=1.32 \mathrm{UCS}$ & 0.518 \\
\hline $\begin{array}{l}\text { CI } \\
\text { COS vs. UCS }\end{array}$ & $\mathrm{COS}=0.82 \mathrm{UCS}$ & -0.493 & $\mathrm{COS}=1.18 \mathrm{UCS}$ & -0.087 & $\mathrm{COS}=1.38 \mathrm{UCS}$ & 0.482 \\
\hline
\end{tabular}


tion is needed (with more cheese samples) to fully understand of how well the COS, compared with USC, differentiates these cheeses and to establish how widely the COS is applicable to other cheeses.

\section{ACKNOWLEDGMENT}

We thank Dairy Manufacturers, Inc. for funding the research and Schreiber Foods, Inc. (Green Bay, WI) for supplying the cheese samples for this study.

\section{REFERENCES}

AOAC. 1995. Official Methods of Analysis, 16th ed. Association of Official Analytical Chemists, Washington, DC.

Arnott, D. R., H. A. Morris, and W. B. Combs. 1957. Effect of certain chemical factors on the melting quality of process cheese. J. Dairy Sci. 40:957-963.

Bradley, R. L., E. Arnold, and D. M. Barbano. 1992. Pages 433-532 in Standard Methods for the Examination of Dairy Products. 16th ed. R. T. Marshall, ed. Am. Public Health Assoc., Washington, DC.
Gunasekaran, S., and M. Ak. 2003. Pages 331-376 in Cheese Rheology and Texture, CRC Press, Boca Raton, FL.

Johnson, M. E., and N. F. Olson. 1985. A comparison of available methods for determining salt levels in cheese. J. Dairy Sci. 68:1020-1024.

Kosikowski, F. V. 1977. Pages 337-340 in Cheese and Fermented Milk Foods. 2nd ed.F.V. Kosikowski and Associates, Brooktondale, NY.

Kuo, M. I., Y. C. Wang, and S. Gunasekaran. 2000. A viscoelasticity index for cheese meltability evaluation. J. Dairy Sci. 83:412-417.

Muthukumarappan, K., Y. C. Wang, and S. Gunasekaran. 1999. Modified Schreiber test for evaluation of Mozzarella cheese meltability. J. Dairy Sci. 82:1068-1071.

Park, J., J. R. Rosenau, and M. Peleg. 1984. Comparison of four procedures of cheese meltability evaluation. J. Food Sci. 49:1158-1162.

Wang, H. H., and D. W. Sun. 2001. Evaluation of the functional properties of Cheddar cheese using a computer vision method. J. Food Eng. 49:49-53.

Wang, H. H., and D. W. Sun. 2002. Melting characteristics of cheese: Analysis of effect of cheese dimensions using computer vision techniques. J. Food Eng. 52:279-284.

Wang, W., P. S. Kindstedt, J. A. Gilmore, and R. G. Ming. 1998 Changes in the composition and meltability of Mozzarella cheese during contact with pizza sauce. J. Dairy Sci. 81:609-614. 